\title{
Neurophysiological identification of a late infantile form of 'neuronal lipidosis'
}

\author{
G. PAMPIGLIONE AND ANN HARDEN \\ From the Department of Neurophysiology, The Hospital for Sick Children, \\ Great Ormond Street, London
}

SUMMARY In the past, the classification of progressive neurological diseases in childhood has been based on either clinical or histological criteria. More recently biochemical aspects have been included ${ }^{\text {¿s }}$ and the resulting terminology has become very complex. As the electrical activity of the brain is a. sensitive indicator of altered cerebral metabolism, the EEG has added further parameters in the $\vec{\omega}$ study of neurometabolic disorders. In the present study 30 children were selected on the basis of ano unusual combination of EEG features: excess of irregular slow activity, spikes, often polyphasic, and very large amplitude discharges in response to low rates of photic stimulation. All these children. suffered from a disease which after an insidious onset progressed with a fairly uniform clinical course? leading to death in a few years. The histological diagnosis was that of 'Batten's disease', but other. patients with the same histological diagnosis did not show either the same EEG features or a similo clinical picture. It is suggested that the EEG features make it possible to identify at an early stage ${ }_{\mathrm{a}} \mathrm{a}$ disease entity within the wider range of conditions sometimes called 'Batten's disease'.

For many years the classification of some progressive neurological diseases in childhood was mainly based on the histological findings from either post mortem or biopsy material. The detection of abnormal accumulation of particular substances with appropriate staining techniques led to the concept of 'storage diseases'. Recent progress in both histochemistry and enzymology has shifted the emphasis from 'storage diseases' to specific disorders of metabolic pathways. However, as new specific enzyme defects are demonstrated, biochemical nomenclature tends to supersede the older neuropathological classifications.

Among the conditions loosely called 'neuronal lipidoses', the biochemical recognition of Tay Sachs disease as one of the gangliosidoses has now been clearly established (Klenk, 1939; Svennerholm, 1962). Other conditions which in the old literature were included under the clinical term of 'amaurotic family idiocy' (AFI) are not yet biochemically classifiable, although several forms have been described clinically and histologically (Batten, 1903; Vogt, 1905; Spielmeyer, 1906; Jansky, 1908; Bielschowsky, 1913;
Batten, 1914). Recently, there has been an i. creasing tendency to use the term 'Battepsis disease' to cover a wide group of conditionts which show apparently similar histological features but evolve with varied clinical symptomatology (Greenfield, Aring, and Landing, 1955; Zeman and Dyken, 1969).

The study of the electrical activity of the ${ }_{\propto}^{\mathbb{D}}$ brain, particularly over the last 25 years, has $\Rightarrow$ added further parameters to the investigation of 3 children with progressive cerebral disorders. As? the electroencephalograph (EEG) represents sensitive monitor of metabolic alterations within the brain, it seems probable that particularo alterations in enzyme patterns will affect in $\frac{5}{3}$ specific ways the metabolism of cells responsible for cerebral electrogenesis. By careful scrutiny of ${ }_{3}$ the EEG features in verified cases of 'lipid storage diseases' special features have been de-J scribed in children with metachromatic leuco- $-\frac{D}{0}$ dystrophy, Krabbe's disease, Tay Sachs disease in contrast with either the late infantile form oro the juvenile form of AFI (Pampiglione, 1961, N 1968; Pampiglione and Lehovsky, 1968; Elling-N son and Schain, 1969; Kliemann, Harden, ando 
Pampiglione, 1969; Mastropaolo, Pampiglione, and Stephens, 1970).

In the present study the EEG features have been used to identify a probable disease entity within the larger group of neurometabolic disorders sometimes called 'Batten's disease', even if at present no specific enzyme defect has yet been recognized.

\section{METHODS}

Out of a total of some 36,000 EEGs seen in this department since the beginning of 1957,30 children ( 20 girls and 10 boys) have been selected because they showed certain distinctive features to be described in detail in our results. These children were mainly referred for EEG studies because of occasional seizures. A total of 87 EEGs were taken on the 30 children between the ages of $2 \frac{3}{4}$ years and 7 years (see Fig. 1). In addition to the EEG studies, nine polyelectromyograms were taken on seven of the children and the visual evoked responses including the electroretinogram were studied on 16 of the children (to be reported separately).

The EEGs were taken with an Offner Type T, 8 channel apparatus with a time constant of $0.3 \mathrm{sec}$ and an amplification of $10 \mu \mathrm{V} / \mathrm{mm}$ pen deflection (sometimes reduced to 18 or $32 \mu \mathrm{V} / \mathrm{mm}$ pen deflection). The upper frequency response of the pens was linear within $10 \%$ to $70 \mathrm{~Hz}$. The paper speed usually employed was $3 \mathrm{~cm} / \mathrm{sec}$. The electrodes were silversilver chloride discs stuck to the scalp with collodion and placed according to measurements from bony landmarks (Pampiglione, 1956). For the polyelectromyogram pairs of electrodes were applied over the biceps and triceps and sometimes also quadriceps and hamstring groups of muscles (Pampiglione, 1966). Contact of all electrodes to the skin was made through a saline jelly and the resistance was lowered to $5-10 \mathrm{~K} \Omega$.

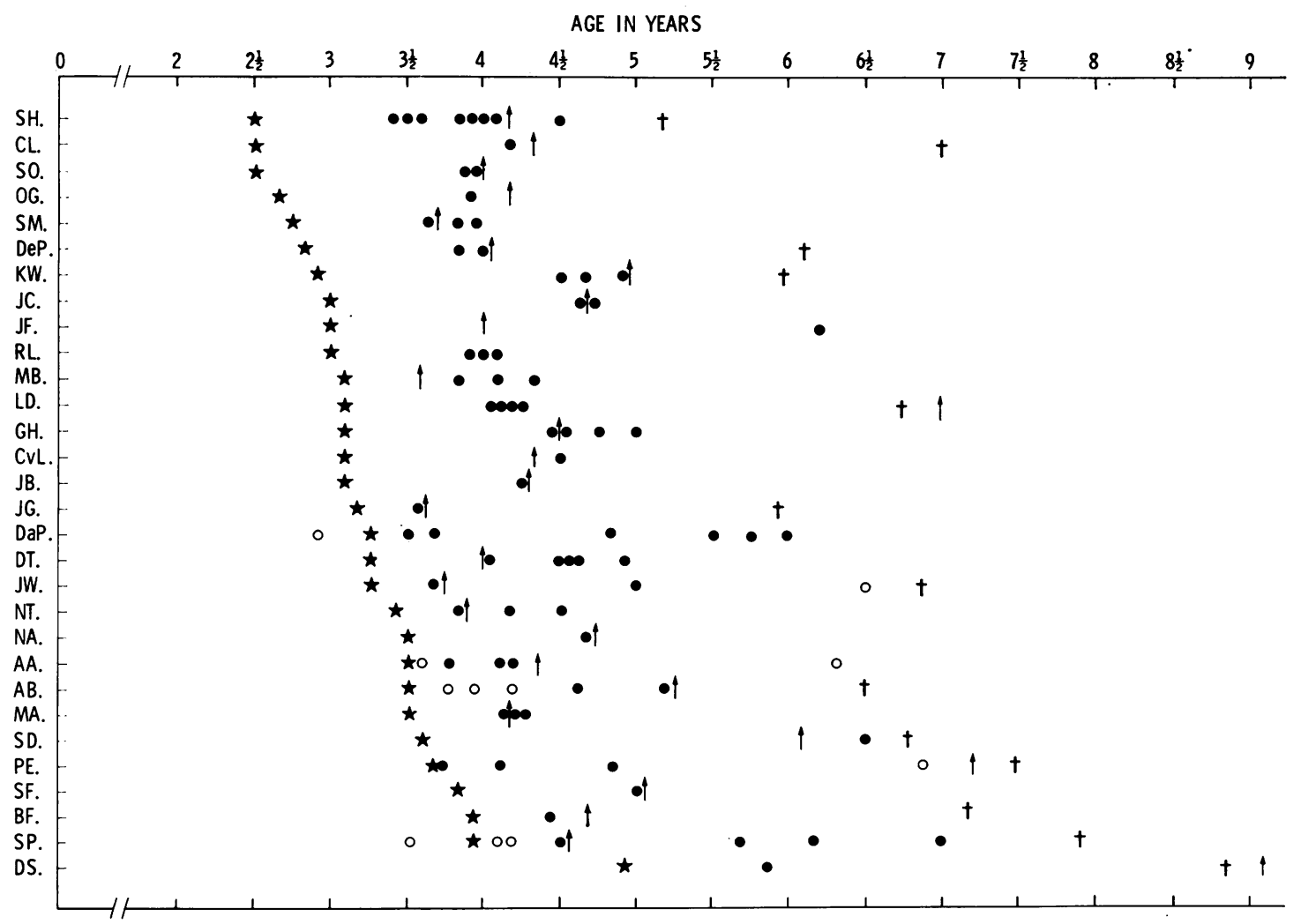

FIG. 1. Timing of EEG studies and histological verification in relation to the course of illness in 30 children. $\dagger=$ death, $\star=$ first fit,$\uparrow=$ histological studies, $\bigcirc=E E G$ without abnormal photic responses, $\bigcirc=E E G$ with abnormal photic responses. 


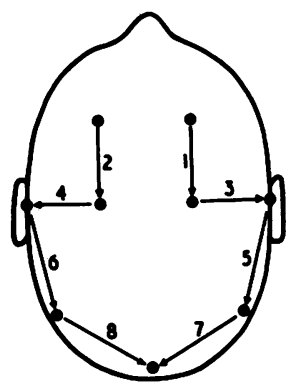

Age 4 yrs.

Age 7 yrs.

$N^{180}$

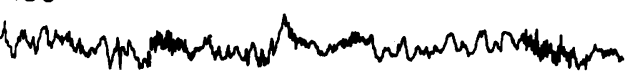

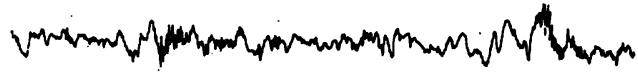

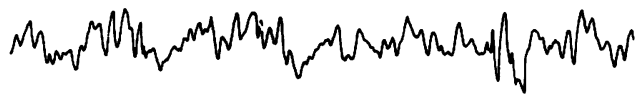

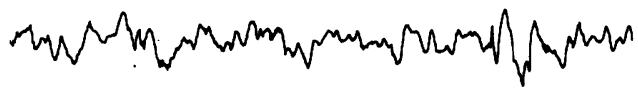

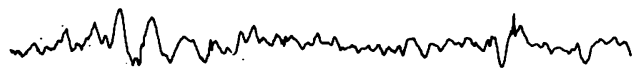

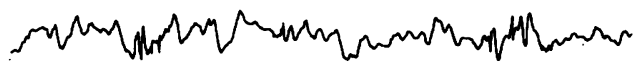

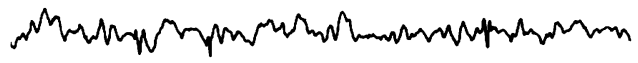

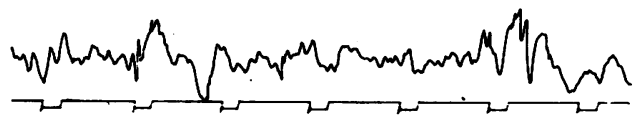

100

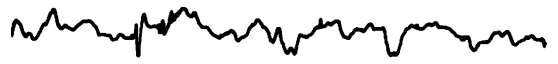

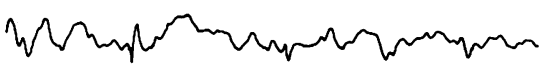

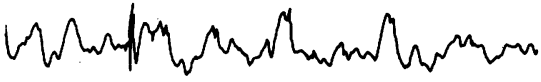

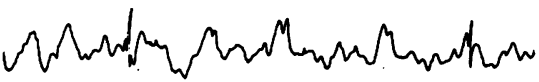

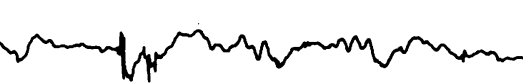

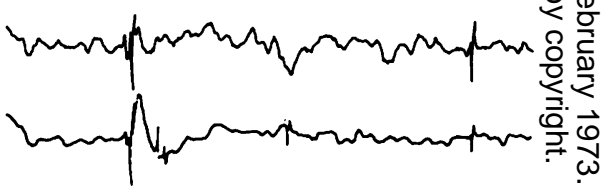

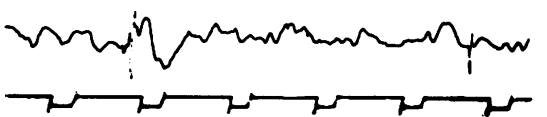

FIG. 2. Typical EEG features at an early (4 years) and late (7 years) phase of the disease. The sensitivity of the amplifiers had to be reduced to $180 \mu \mathrm{V}$ for the calibration signal on the left compared with $100 \mu \mathrm{V}$ for the same signal on the right (same patient).

Photic stimulation from a gas discharge lamp (SLE photic stimulator) was carried out on all the patients usually with the eyes open (except for patients asleep at the time). The lamp was placed at a distance of $20-30 \mathrm{~cm}$ from the eyes and the flashes were presented over a period of half a minute at a slowly changing rate from $2 / \mathrm{sec}$ up to $30 / \mathrm{sec}$ and back to $2 / \mathrm{sec}$ (according to our departmental technique). In addition, short bursts of flashes were presented at slow rates ( 2 to $3 / \mathrm{sec}$, occasionally as isolated flashes) as well as at faster rates. Great care was taken to ensure that the lamp (held manually) was directly in front of the child's eyes even during rapid movements of the child's head.

Although most of the records were taken during wakefulness, either spontaneous or induced sleep (quinalbarbitone) was studied on 11 occasions on seven children at various stages of the disease.

Of the 30 children 12 were known to have died between the ages of 5 and $7 \frac{1}{2}$ years and another died at 9 years. At the present time 12 are known to be still alive between the ages of 4 and 7 years and the outcome of the other six is unknown.

In 26 of the 30 children either a cerebral or a rectal 

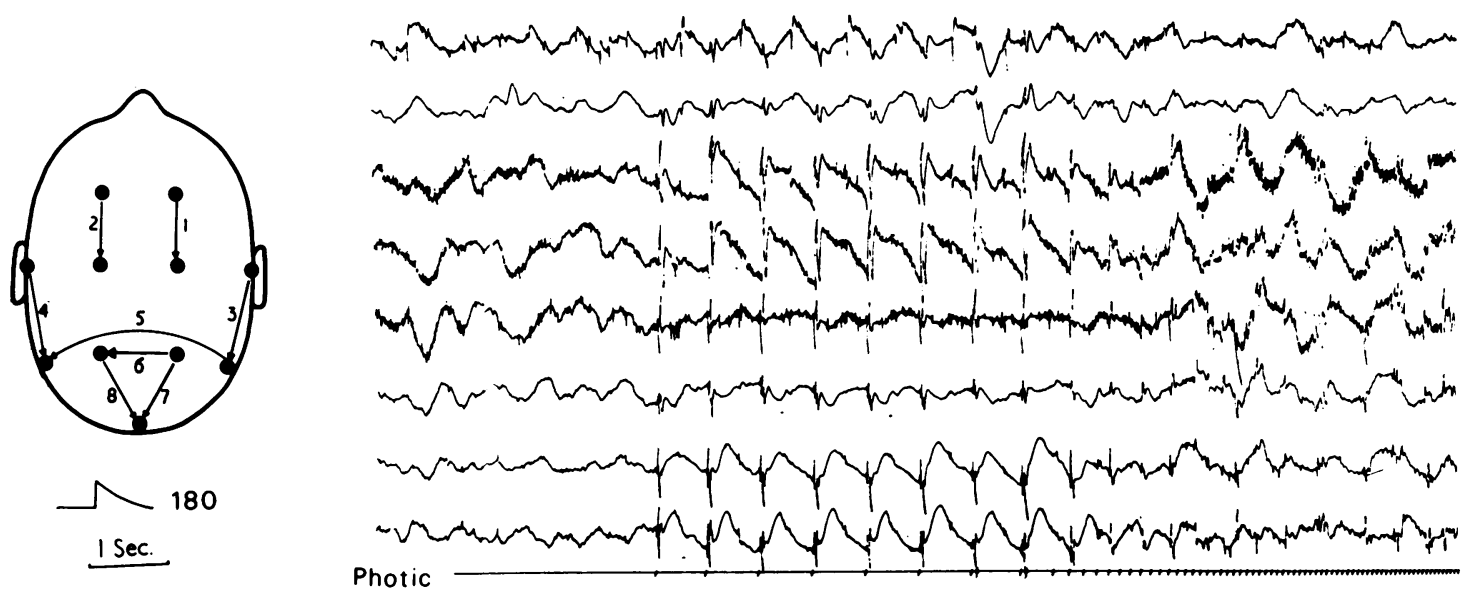

FIG. 3. Age 3 years, 11 months. Typical responses to photic stimulation with large amplitude discharges for low rate of flash (marked on bottom trace). The discharges tend to become smaller and less closely related to the flashes when the rate of flash is increased.

biopsy was carried out which showed extensive neuronal degeneration with features of 'neuronal lipidosis' and excessive amounts of lipofuscin-like intracellular material. Of the remaining four, two had similar histological features verified at necropsy; one had a cerebral biopsy in 1959 but the specimen was accidentally spoilt; and the last child was a sibling of an already verified case (with similar clinical course and EEG features) in whom no biopsy was considered.

\section{RESULTS}

EVOLUTION OF CLINICAL FEATURES In all the 30 children the clinical evolution was fairly uniform in spite of the insidious onset of symptoms such as a slight developmental delay and some clumsiness, often noticed only in retrospect. However, between the ages of $2 \frac{1}{2}$ and nearly 4 years (except for one child at nearly 5 years), the first seizure occurred (Fig. 1). Some impairment of speech and occasional jerkiness of the limbs were often noticed between $2 \frac{1}{2}$ and $3 \frac{1}{2}$ years of age as fairly early symptoms. Later more obvious myoclonic. phenomena became increasingly prominent with gross disruption of voluntary activity. Progressively, there was an inability to walk and to feed without help and generalized seizures became increasingly frequent, often preceded by a crescendo of myoclonic jerks. None of the children had any obvious visual difficulties, at least until an advanced stage of the disease when vision could no longer be assessed clinically. Mental and motor deterioration occurred over a period of several months until the child became bedridden with limited contact with his environment, incontinent, with severe flexor contractures of the limbs and prolonged bouts of status myoclonicus largely unaffected by drugs. Death occurred after three to five years of illness.

EVOLUTION OF EEG FEATURES None of the normal rhythmic activity in the occipital region elicited by eye closure (alpha rhythm) was recognizable in any of the 30 children over a fairly long period of the disease. The rhythmic activity in the Rolandic regions which in this age group is at about $8-10 \mathrm{~Hz}$ (and not affected by eye opening) was also disrupted, although to a lesser extent than the alpha rhythm. There was, instead, a considerable amount of irregular $2-7 / \mathrm{sec}$ activity usually of an amplitude reaching 200-500 $\mu \mathrm{V}$. This activity was, at first, larger over the posterior than over the anterior half of the two hemispheres but as the disease progressed it became of greater amplitude anteriorly. In addition, spikes, or sharp waves, appeared (at first only infrequently) reaching 100-200 $\mu \mathrm{V}$, sometimes polyphasic. These discharges tended to occur as single transients with variable 
lateralized preponderance. Often in one or other area these discharges consisted of polyphasic spikes irregularly accompanied or followed by a somewhat larger slow wave (Fig. 2): the phase relationship between short and long duration components was always variable. Sometimes but not always a twitch of a muscle or a jerk of a limb was seen about the same time as the discharges in the EEG.

In the patients who fell asleep during the test there was little EEG change and on no occasion did sleep spindles appear, although in some patients marked fluctuations in the amount and amplitude of the slow activity occurred over a wide area of the two hemispheres. In response to sudden noises whether during sleep or in the waking state, there was only occasionally a prolonged startle response. In one patient in whom a small dose of intravenous methohexitone was given, no fast activity appeared and there was only a moderate increase in irregular $7-15 \mathrm{~Hz}$ waves with only a slight diminution in discharges which persisted throughout.

At an early stage, passive eye closure elicited some increase in irregular slow activity over the posterior half of the head occasionally accompanied by a slight increase in discharges but later there was no detectable change either after eye opening or eye closure. Voluntary hyperventilation was not possible in these children because the general condition of the patient made active cooperation impossible. There was no constant asymmetry between the activities of the two hemispheres at any stage of the disease.

One of the most striking EEG features seen in all patients was the appearance of large amplitude spikes in response to single flashes of light, or at flickering rates below 3 flashes/sec. These large discharges reaching 50 to $500 \mu \mathrm{V}$ were usually polyphasic and maximal in the posterior half of the two hemispheres. When the flickering rate was increased to 4 or more flashes/sec there was a diminution in the size of the evoked discharges which tended to recur at a rate slower than that of the flashes (Fig. 3). Sometimes jerks of the limbs and of the muscles of the face were seen about the same time as the cerebral responses to the flashes, but at other times jerking was induced which was not directly related to the flickering rate. On occasions jerking persisted for a few seconds after cessation of photic stimula- tion, leading to major convulsions in two children. The discharges decreased considerably if the patient did not directly look at the light but persisted during either spontaneous or induced sleep.

In four children the abnormal responses to photic stimulation were not obvious when first tested before, or soon after the first seizure (Fig. 1) but the typical pattern became apparent on subsequent testing. In those patients in whom we were able to repeat EEG studies over a period of years, a general diminution in the amplitude of all activities gradually occurred. Also the spontaneous discharges in the EEG diminished in spite of the increasing episodes of status myoclonicus. Photic stimulation however continued to evoke the peculiar abnormal discharges in all but three patients in a terminal phase (Fig. 1).

Whenever a polyelectromyogram was recorded together with the EEG it became apparent that some of the myoclonic phenomena were time-linked both to the spontaneous EEG disocharges and to those elicited by photic stimula $\overrightarrow{\$}$ tion. However, on many occasions single of grouped spikes were recorded from the muscles and occurred independently from the EEG dise charges, often more frequently.

\section{DISCUSSION}

The possibility that the EEG findings may be utilized to recognize some of the "neuronal lipidoses' in childhood was originally implied by Cobb, Martin, and Pampiglione (1952). At the time, however, both the EEG techniques and the interpretation of the histological features were somewhat different from those in current practice. Carels (1960) was the first to describe in detail abnormally large somatosensory and photic responses in two siblings with 'late infantile amaurotic family idiocy'. However, Carels was mainly concerned with the temporal relationship between cerebral discharges and myoclonic phenomena and did not stress any diagnostic importance of the EEG features.

The abnormally large responses to low rates of photic stimulation described in the present paper are quite different from the bursts of discharges commonly seen in most photosensitive subjects in whom the critical rate of flash is at about $15-20 / \mathrm{sec}$. Unless the flashing rate is slow 
(1 to $3 / \mathrm{sec}$ ) the peculiar discharges seen in children with this disorder may be completely missed.

The diagnostic value of the EEG features, particularly the peculiar responses to low rates of brief photic stimuli, was originally reported in a small group of patients with a particular type of 'neuronal lipidosis' (Pampiglione, 1961). These observations, confirmed by further work (Pampiglione, 1968; Pampiglione and Lehovsky, 1968), were not reported by other authors until Green (1971) described similar EEG findings as a new phenomenon in only seven of his patients considered to be suffering from 'Batten's disease'. His 20 patients were aged from 2 to 23 years and had somewhat varied clinical symptomatology. Green's conclusion that there was no single neurophysiological finding pathognomonic of 'Batten's disease' is probably justified in view of the heterogeneity of this material.

All the patients reported in our paper had similar EEG features and developed a disorder with fairly similar subsequent clinical evolution. This would suggest that our 30 patients suffered from a condition which can be distinguished at an early stage on EEG grounds. It is interesting to note that most of our 30 cases had been referred for EEG studies under the broad heading of 'epilepsy' either with or without 'mental retardation'; this reflects the difficulty of an early clinical recognition of this severe disease. As yet we do not know at what presymptomatic stage the characteristic EEG features may appear as we have not been able to examine a sufficient number of younger siblings of affected patients.

Over the years the classification of 'neuronal lipidoses' has varied a great deal. The age of the patient was for a while considered important as a distinguishing factor and led to groupings such as 'infantile', 'late infantile', 'juvenile', and 'adult' forms and even a 'congenital' form of AFI. Other authors preferred to use descriptive terms such as 'the myoclonic variant of cerebral lipidosis' (Seitelberger, 1967). However, considerable differences in individual clinical patterns have been recognized for a long time and the classification tended also to include the use of eponyms related partly to clinical and partly to histological features (Batten, BielschowskyJansky, Spielmeyer-Vogt, etc.). Further con- fusion is due to the fact that F. E. Batten (1903) described two siblings aged 4 and 6 years with failing vision and mental deterioration (one with temper tantrums, the other with fits). F. E. Batten (1914) also described two siblings with fits beginning at the age of about 3 years and increasing mental defect; in this paper however, he called the condition 'juvenile form of AFI'. However, R. D. Batten (1897) had already described two older siblings with failing vision from 14 years who showed macular changes similar to those later described by F. E. Batten.

More recently the term 'neuronal ceroid lipofuscinosis' (NCL) was introduced by Zeman and Dyken (1969) as a neuropathological description of 'Batten's disease': these authors included patients with a variety of symptoms beginning between 1 and 23 years of age. The term NCL describes the histological aspects of the intraneuronally stored material which, however, has not yet been identified chemically. According to both Zeman and Dyken, and to Cavanagh (1970), this term cuts across several subgroups of AFI but excludes the gangliosidoses. Other more chemically oriented experts go as far as questioning whether 'Batten's disease' meets the histochemical requirements of a lipid storage disorder (Fredrickson, 1968; Svennerholm, 1969).

Among the patients seen in our department and eventually classified as 'Batten's disease' on histological grounds, only these 30 children showed uniform early EEG features and later clinical evolution. This suggests that the histological findings at present are not sufficiently specific to distinguish different disease processes within the mixed group of conditions which some authors label as 'Batten's disease'.

In progressive diseases affecting the central nervous system of children, the normal developmental changes in the electrical activity of the brain may be altered by the evolution of the disease process. At present, we do not know the precise biochemical nature of the familial disease described in this paper but it appears that the identification of the condition can be based on EEG features. Such EEG identification should help research workers in other fields such as biochemistry, histochemistry, and enzymology to look for specific differential features in these patients at present indiscriminately grouped under broader terms such as 'NCL', 'neuronal 
lipidoses', or 'Batten's disease'. This progressive condition detectable by simple EEG studies should be recognized as early as possible in view of its prognosis and genetic implications even if at present no effective treatment is known.

It is a pleasure to acknowledge the help of our colleagues who referred the patients for neurophysiological investigations, in particular Dr. E. Brett, Dr. P. R. Evans, the late Dr. Paul Sandifer, Dr. Rosemary Stephens, and Dr. J. Wilson. We also wish to thank Dr. Brian Lake for information about the histochemical findings and The British TaySachs Foundation for secretarial help.

\section{REFERENCES}

Batten, F. E. (1903). Cerebral degeneration with symmetrical changes in the maculae in two members of a family. Transactions Ophthalmological Society U.K., 23, 386-390.

Batten, F. E. (1914). Family cerebral degeneration with macular change (so-called juvenile form of family amaurotic idiocy). Quarterly Journal of Medicine, 7, 444-454.

Batten, R. D. (1897). Two brothers with symmetrical disease of the macula, commencing at the age of fourteen. Transactions Ophthalmological Society U.K., 17, 48-49.

Bielschowsky, M. (1913). Über spätinfantile familiäre amaurotische Idiotie mit Kleinhirnsymptomen. Deutsche Zeitschrift für Nervenheilkunde, 50, 7-29.

Carels, G. (1960). Etude physiopathologique d'un syndrome myoclonique chez deux enfants atteints d'une forme infantile tardive de l'idiotie amaurotique. Essai de corrélation anatomophysiopathologique. Acta Neurologica et Psychiatrica Belgica, 60, 435-464.

Cavanagh, J. B. (1970). Batten's disease-a separate entity? Developmental Medicine and Child Neurology, 12, 377-378.

Cobb, W., Martin, F., and Pampiglione, G. (1952). Cerebral lipidosis: an electroencephalographic study. Brain, 75, 343357.

Ellingson, R. J., and Schain, R. J. (1969). EEG patterns in juvenile cerebral lipidosis. Electroencephalography and Clinical Neurophysiology, 27, 191-194.

Fredrickson, D. S. (1968). Classification and features of the lipidoses affecting the nervous system. Pathologia Europaea, 3, 121-142.

Green, J. B. (1971). Neurophysiological studies in Batten's disease. Developmental Medicine and Child Neurology, 13, 477-489.

Greenfield, J. G., Aring, C. D., and Landing, B. H. (1955). Clinical pathologic conference. Case presentation. Neurology (Minneap.), 5, 732-739.
Jansky, J. (1908). Sur un cas jusqu'à présent non décrit d'idiotie amaurotique familiale compliqué par une hypoplasie du cervelet. Sbornik Vëdeckých Praci Lekařské Fakulty Karlovy University V Hradci Králové, 9, 165-196.

Klenk, E. (1939). Beiträge zur Chemie der Lipoidosen, Niemann-Picksche Krankheit und amaurotische Idiotie. Hoppe-Seyler's Zeitschrift Physiologische Chemie, 262, 128143.

Kliemann, F. A. D., Harden, A., and Pampiglione, G. (1969). Some EEG observations in patients with Krabbe's disease. Developmental Medicine and Child Neurology, 11, 475-484.

Mastropaolo, C., Pampiglione, G., and Stephens, R. (1971). EEG studies in 22 children with sulphatide lipidosis (metachromatic leucodystrophy). Developmental Medicine and Child Neurology, 13, 20-31.

Pampiglione, G. (1956). Some anatomical considerations upon electrode placement in routine EEG. Proceedings Electrophysiological Technologists' Association, 7, No. 1, 20-30.

Pampiglione, G. (1961). EEG in some inborn errors of metabolism. Pp. 53-63. Proceedings of the VII International Congress of Neurology, Rome, 1961. Vol. I. Società Grafica Romana: Rome.

Pampiglione, G. (1966). Normal and abnormal coordination or movements: a polymyographic approach. Journal of Neurological Sciences, 3, 525-538.

Pampiglione, G. (1968). Some inborn metabolic disorders affecting cerebral electrogenesis. In Some Recent Advances in Inborn Errors of Metabolism, pp. 80-98. Edited by K. S. Holt and V. P. Coffey. Livingstone: Edinburgh.

Pampiglione, G., and Lehovský, M. (1968). The evolution of EEG features in Tay-Sachs' disease and amaurotic family idiocy in $\mathbf{2 4}$ children. In Clinical Electroencephalography of Children, pp. 287-306. Edited by P. Kellaway and IO Petersen. Almqvist and Wiksell: Stockholm.

Seitelberger, F., Jacob, H., and Schnabel, R. (1967). Theo myoclonic variant of cerebral lipidosis. In Inborn Disorders of Sphingolipid Metabolism, pp. 43-74. Edited by S. M Aronson and B. W. Volk. Pergamon Press: Oxford.

Spielmeyer, W. (1906). Über eine besondere Form von familiärer amaurotischer Idiotie. Neurologisches Centralblatt, 25, 51-55.

Svennerholm, L. (1962). The chemical structure of normal human brain and Tay-Sachs gangliosides. Biochemical and Biophysical Research Communications, 9, 436-441.

Svennerholm, L. (1969). Classification of lipidoses. Pp. 58-59. In Second International Meeting of the International Society for Neurochemistry. Edited by R. Paoletti, R. Fumagalli and $\mathrm{C}$. Galli. Tamburini: Milano.

Vogt, H. (1905). Über familiäre amaurotische Idiotie und verwandte Krankheitsbilder. Monatsschrift für Psychiatrie und Neurologie, 18, 161-171.

Zeman, W., and Dyken, P. (1969). Neuronal ceroid-lipofuscinosis (Batten's disease): relationship to amaurotic family idiocy. Pediatrics, 44, 570-583. 